\title{
High Body Mass Index and its Effect on Total Knee Replacement
}

\author{
Dr Anshul S Sobti ${ }^{1^{*}}$ and Mr. Joseph E Sudhakar ${ }^{2}$ \\ ${ }^{1}$ International Training Fellow Trauma \& Orthopaedics, Darlington Memorial Hospital, County Durham and Darlington Hospital NHS Trust, Hollyhurst Road, Darlington, \\ DL3 $6 H X$, United Kingdom
}

${ }^{2}$ Consultant Trauma \& Orthopaedics, Darlington Memorial Hospital, County Durham and Darlington Hospital NHS Trust, Hollyhurst Road, Darlington, DL3 6HX, United Kingdom

*Corresponding author: Dr Anshul Sobti, International Training Fellow Trauma \& Orthopaedics, Darlington Memorial Hospital, County Durham and Darlington Hospital NHS Trust, Hollyhurst Road, Darlington, DL3 6HX, United Kingdom, Tel: +447423603881; E-mail: anshulsobti@gmail.com

Received date: July 10, 2017; Accepted date: July 12, 2017; Published date: July 14, 2017

Copyright: (C) 2017 Sobti AS, et al. This is an open-access article distributed under the terms of the Creative Commons Attribution License, which permits unrestricted use, distribution, and reproduction in any medium, provided the original author and source are credited.

\section{Introduction}

Osteoarthritis (OA) is the leading cause of disability and knee OA alone affects over 250 million people worldwide [1]. Joint arthroplasty for knee is one of the most common elective and cost effective surgical intervention for end stage lower-limb arthritis [1]. The National Joint Registry (NJR) indicates that by the year 2030 the demand for total knee replacement (TKR) will be nearly 3.5 million cases. The current cost burden to the National Health Service (NHS) is enormous and its estimated to rise in excess of $£ 7000$ per case [2]. This will have a huge bearing on the already cash crushed health care system.

As a population the UK is becoming older and increasingly obese. Data released in 2012 revealed that $26.2 \%$ of the UK adult population are obese (i.e. body mass index (BMI) $>30 \mathrm{~kg} / \mathrm{m}^{2}$ ) compared to $13.2 \%$ in 1993 [3]. NJR supports this observation, demonstrating that the number of elective primary TKR procedures performed in obese patients (BMI $>30 \mathrm{~kg} / \mathrm{m}^{2}$ ) is increasing. Twenty Six \% of patients undergoing primary hip arthroplasty in 2011 were obese compared with $21 \%$ in 2004 . Thirty two $\%$ of patients that received a TKR in 2011 were obese compared with $28 \%$ in 2004 [3]. Based on changing population demographics of age, sex, BMI; in the year 2035, about $1,219,362$ TKRs will be carried out [4]. Given the prevalence of obesity, a significant percentage of these cases will be in patients outside the normal BMI range $[5,6]$.

Both biomechanical and physiological mechanisms are compromised by obesity leading to the development of OA. Higher BMI results in elevated loading forces over the articular cartilage eventually causing tissue damage. Thereby obesity contributes to a higher rate of OA and ultimately total joint arthroplasty utilization. There are criticisms of using BMI as a measure of obesity. Due to the fact that it does not distinguish between weight associated with muscle versus weight associated with adipose tissue. However, it is widely accepted as a measure of obesity due to the ease of data collection for large cohorts [7].

\section{Current Issue}

Prospective evidence that obesity is a significant causal factor in the initiation of knee OA has been provided by the Framingham Study

[6]. It has been proved that this increase is weight-related. Oliveria and co-workers demonstrated that the odds ratio for incident symptomatic OA knee increases dramatically with increasing BMI at $\mathrm{BMI} \leq 25.5$ with odds ratio of 1.0 , at BMI 25.5-30 the odds ratio is 3.8, and at BMI $>30$ the odds ratio increased to $9.3[1,8]$. Apart from OA, obesity facilitates a number of other secondary pathologies including cardiac disease, diabetes mellitus, hypertension, and dyslipidemia, which, in turn, heighten the complexities of these conditions [9].

While literature may points out an increase in perioperative complications associated with total joint replacement for obese patients, these must be balanced against the benefits of decreased pain and increased function

[10]. Although obesity is assumed to bring out a negative influence on survival of TKR, there is no definitive proof in literature. Only few studies have reported significant lower functional outcomes in obese patients compared with non-obese patients, also there are questions on the power of these studies [11].

The impact of obesity on the outcomes of TKA is still debated. A recent systematic review of the literature [11] showed that deep infection and revision for any reason were more often in obese patients than in non-obese patients, but another recent systematic review [12] found that overall obese patients did not have significantly lower knee function scores and implant survivorship than those non-obese, although the outcomes were significantly worse in the morbidly obese. However, most of the previous studies were retrospective and reported small series with short-term follow-ups [13]. Therefore there is no consensus on the matter. The impact of obesity on the outcome of joint arthroplasty surgery remains controversial. The current difficult financial climate has made it even more difficult and there is a conscious drive towards reducing costs within the UK National Health Service (NHS).

It is important to realize the full impact of obesity on arthroplasty surgery [14-16]. Fears of poorer outcomes and increased financial costs associated with joint replacement surgery in the obese patient have already lead some trusts within the UK to ration hip replacement and TKR, barring joint arthroplasy access to patients with a BMI over 30 $\mathrm{kg} / \mathrm{m}^{2}$. Despite the increased risks obese patients do benefit from arthroplasty surgery $[17,18]$. It is therefore difficult to justify withholding this surgery based on BMI alone $[18,19]$.

\section{Conclusion}

It is widely accepted that TKR has proved to stand the test of time in treatment for OA and it has revolutionized care and improved quality of life [8]. Success of surgical therapy has led to budgetary restriction, enforced by Health Care Systems. This has raised questions not only upon surgeons but also on the Government. Queries regarding limitations to access for joint arthroplasty surgery have cropped up. Early indications of this has come from the East Suffolk health board (UK) trust instructing surgeons to prioritize patients for lower limb joint replacement surgery based on their BMI, arguing on the grounds 
Citation: Sobti AS, Sudhakar JE (2017) High Body Mass Index and its Effect on Total Knee Replacement. J Arthritis 6: 245. doi: 10.4172/2167-7921.1000245

Page 2 of 2

of increased risks to the patient and reduced postoperative efficacy of the surgery in obese patients. This has led to a great deal of controversy. There is no clear evidence that obesity is a strong predictor of poorer functional outcomes. Functional outcomes are partly subjective, and represent only one aspect of the potential implications of obesity on TKR, and this warrants a structured systematic review to clear the controversy.

\section{References}

1. Felson D, Naimark A, Anderson J, Kazis L, Castelli W, et al. (1987) The prevalence of knee osteoarthritis in the elderly. The framingham osteoarthritis study. Arthritis Rheum 30: 914-918.

2. Jenkins P, Clement N, Hamilton D, Gaston P, Patton J, et al. (2013) Predicting the cost-effectiveness of total hip and knee replacement: A health economic analysis. Bone Joint J 95: 115-121.

3. Bradley BM, Griffiths SN, Stewart KJ, Higgins GA, Hockings M, et al. (2014) The effect of obesity and increasing age on operative time and length of stay in primary hip and knee arthroplasty. J Arthroplasty 29: 1906-1910.

4. Culliford D, Maskell J, Judge A, Cooper C, Prieto-Alhambra D, et al. (2015) Future projections of total hip and knee arthroplasty in the UK: results from the UK Clinical Practice Research Datalink. Osteoarthritis Cartilage 23: 594-600.

5. Workgroup of the American Association of Hip and Knee Surgeons Evidence Based Committee (2013) Obesity and total joint arthroplasty: a literature based review. J Arthroplasty 28: 714-721.

6. Horan F (2006) Obesity and joint replacement. J Bone Joint Surg Br 88: 1269-1271.

7. Rajgopal V, Bourne RB, Chesworth BM, MacDonald SJ, McCalden RW, et al. (2008) The Impact of Morbid Obesity on Patient Outcomes After Total Knee Arthroplasty. J Arthroplasty 23: 795-800.

8. Gillespie GN, Porteous AJ (2007) Obesity and knee arthroplasty. The Knee 14: 81-86.
9. Jones CA, Cox V, Jhangri GS, Suarez-Almazor ME (2012) Delineating the impact of obesity and its relationship on recovery after total joint arthroplasties. Osteoarthritis Cartilage 20: 511-518.

10. Foran JRH, Mont MA, Etienne G, Jones LC, Hungerford DS (2004) The outcome of total knee arthroplasty in obese patients. J Bone Joint Surg Am 86: 1609-1615.

11. Kerkhoffs GMMJ, Servien E, Dunn W, Dahm D, Bramer JA, et al. (2012) The Influence of Obesity on the Complication Rate and Outcome of Total Knee Arthroplasty. J Bone Joint Surg Am 94:1839-1844.

12. McElroy M, Pivec R, Issa K, Harwin S, Mont M (2013) The Effects of Obesity and Morbid Obesity on Outcomes in TKA. J Knee Surg 26: 83-88.

13. Lizaur-Utrilla A, Miralles-Muñoz FA, Sanz-Reig J, Collados-Maestre I (2014) Cementless Total Knee Arthroplasty in Obese Patients. J Arthroplasty 29: 1192-1196.

14. Smith IDM, Elton R, Ballantyne JA, Brenkel IJ (2008) Pre-operative predictors of the length of hospital stay in total knee replacement. J Bone Joint Surg Br 90: 1435-1440.

15. Foote J, Panchoo K, Blair P, Bannister G (2009) Length of Stay Following Primary Total Hip Replacement. Ann R Coll Surg Engl 91: 500-504.

16. Husted H, Holm G, Jacobsen S (2008) Predictors of length of stay and patient satisfaction after hip and knee replacement surgery: fast-track experience in 712 patients. Acta Orthop 79: 168-173.

17. Davis A, Wood A, Keenan A, Brenkel I, Ballantyne J (2011) Does body mass index affect clinical outcome post-operatively and at five years after primary unilateral total hip replacement performed for osteoarthritis?: a multivariate analysis of prospective day. J Bone Joint Surg $\mathrm{Br}$ 93: 1178-1182.

18. Dowsey M, Liew D, Stoney J, Choong P (2010) The impact of preoperative obesity on weight change and outcome in total knee replacement: a prospective study of 529 consecutive patients. J Bone Joint Surg Br 92: 513-520.

19. Dowsey M, Liew D, Choong P (2011) Economic burden of obesity in primary total knee arthroplasty. Arthritis Care Res (Hoboken) 63: 1375-1381. 